\title{
Correlation between In Vivo and In Vitro Efficacy of Antimicrobial Agents against Foreign Body Infections
}

\author{
A. F. Widmer, R. Frei, Z. Rajacic, and W. Zimmerli
}

From the Departments of Internal Medicine and Research and the Bacteriology Laboratory, University Hospital, Basel, Switzerland

\begin{abstract}
Implant-associated infections are often resistant to antibiotic therapy. Routine sensitivity tests fail to predict therapeutic success. Therefore experimental in vitro tests were sought that would better correlate with drug efficacy in device-related infections. The activity of six different antibiotics against methicillin-resistant Staphylococcus epidermidis was investigated. In vivo studies were performed with the guinea pig tissue-cage animal model; in vitro studies with minimum inhibiting and bactericidal concentrations, time-kill studies of growing and stationary-phase microorganisms, the killing of glass-adherent S. epidermidis. Drug efficacy on stationary and adherent microorganisms, but not minimum inhibiting concentrations, predicted the outcome of device-related infections. Rifampin cured 12 of 12 infections and was also the most efficient drug in any experimental in vitro test. Similarly, the failure of ciprofloxacin to eradicate foreign body infections correlated with its low efficacy on stationary-phase and adherent $S$. epidermidis.
\end{abstract}

Device-related infections often persist until the device is removed, even if the given antibiotic has a low minimum inhibiting concentration (MIC) for the causing microorganism [1]. The preferential bacterial colonization of biomaterials plus a local immunodeficiency explain the high infective susceptibility of implants and the persistence of such infections [2-4]. Bacteria develop a survival mode by adhering to inert surfaces and producing a biofilm [5-7]. Possibly the mode of growth and the adherence of bacteria to bioimplants explain the failure of certain antibiotics to cure device-related infections.

To date, no standardized antimicrobial susceptibility test is available to evaluate drug activity on adherent bacteria. MIC and minimum bactericidal concentration (MBC) evaluate the drug efficacy on planktonic bacteria in logarithmic phases of growth $[8,9]$, a situation far from that of adherent bacteria [5]. The activity of many antimicrobial agents strictly depends on the phase of bacterial growth [10]. MICs and MBCs are much higher for most drugs if tests are performed with partly adherent bacteria [11].

In the present study, we tested the efficacy of different antimicrobial agents in the treatment of guinea pig implant infections caused by a weak slime-producing strain of Staphylococcus epidermidis. To evaluate the in vitro efficacy

Received 30 May 1989; revised 6 November 1989.

Presented in part at the 28th Interscience Conference on Antimicrobial Agents and Chemotherapy, Los Angeles, October 1988.

Financial support: Lilly Researčh Laboratories, Indianapolis, and Hyland Therapeutic Divisions, Travenol Laboratories, Glendale, CA (to A. F. W.). W. Z. received a career development award from the Swiss National Science Foundation.

Reprints and correspondence: Dr. W. Zimmerli, Departments of Medicine and Research, University Hospital, CH-4031 Basel, Switzerland.

The Journal of Infectious Diseases 1990;162:96-102 (c) 1990 by The University of Chicago. All rights reserved. $0022-1899 / 90 / 6201-0015 \$ 01.00$ of antibiotics, we modified the MBC test procedure and developed a novel assay for testing adherent bacteria. We analyzed parameters that could predict the clinical outcome of device-related infections by comparing pharmacokinetic parameters, routine-susceptibility tests, and drug efficacy on nongrowing and adherent staphylococci in an experimental model of foreign body infections $[2,3,12]$.

\section{Materials and Methods}

Bacteria and antibiotics. The test strain for most experiments was a methicillin-resistant $S$. epidermidis. This strain (B3972) was a clinical isolate from a blood culture of a patient with catheter-related septicemia. Identification was determined by a Staphident strip (API, La Balme les Grottes, France). It had a distinct susceptibility pattern including resistance to methicillin, cotrimoxazole, erythromycin, gentamicin, and tobramycin and sensitivity of ciprofloxacin, vancomycin, daptomycin, teicoplanin, and netilmicin. Such an antimicrobial susceptibility pattern is known to be as discriminating as plasmid profile analysis [13]. The $S$. epidermidis $\mathrm{B} 3972$ revealed weak slime production $[14,15]$.

For control experiments, a rifampin-resistant variant of $S$. epidermidis B3972 (MIC $>4 \mu \mathrm{g} / \mathrm{ml}$ ) was selected by serial exposure of bacteria to increasing subinhibitory concentrations of rifampin. With this strain we tested whether a possible synergistic effect of rifampin combinations would depend on the bacterial killing of rifampin or on a nonspecific property (e.g., antiadherent effect) of this drug. In some experiments another strain, a moderate-to-strong slime-producing, methicillin-resistant $S$. epidermidis (ATCC 35983) was used [15]. Working cultures were maintained on blood agar and transferred weekly. A new aliquot of the initial strain, stored in skim milk at $-70^{\circ} \mathrm{C}$, was cultured every 3 months.

Slime production was qualitatively determined [14]. Control experiments to exclude bacterial clumping were performed by direct microscopy and serial sonication of samples $\leqslant 9 \mathrm{~min}$ with $60 \mathrm{~W} / \mathrm{min}$ (Labsonic 2000; B. Braun Instruments, Burlingame, CA). Bacterial clumping was not observed with either method. The following antimicrobial agents, provided by the manufacturers, were evaluated: 
ciprofloxacin (Bayer AG, Wuppertal, FRG), rifampin (Ciba-Geigy, Basel, Switzerland), netilmicin (Schering, Kenilworth, NJ), vancomycin and daptomycin (Eli Lilly, Indianapolis), and teicoplanin (LePetit, Milan, Italy).

Animal model. We used a previously described foreign-body animal model [2, 3, 12]. In brief, four sterile polytetrafluorethylene (Teflon) tubes $(32 \times 10 \mathrm{~mm})$, perforated by 130 regularly spaced holes (tissue cages; Ciba-Geigy) were aseptically implanted into the flanks of albino guinea pigs weighing $600-1100 \mathrm{~g}$. Experiments were started after complete healing of wounds, $\sim 2-4$ weeks after surgery. Before each experiment, interstitial fluid accumulating in the tissue cages was checked for sterility.

At day 0 , for each experiment, 16 tissue cages were infected by local inoculation of $10^{4} \mathrm{cfu}$ of $S$. epidermidis. At day 1 , infection was confirmed by quantitative cultures of the tissue-cage fluid. Twenty-four hours after inoculation, antibiotic therapy was started. Each drug was given every $12 \mathrm{~h}$ for 4 days (total eight doses). Application was intraperitoneal (ip) except for netilmicin, which was given intramuscularly (im). In any experiment, one untreated animal with four cages served as a control. Tissue-cage fluid was aspirated daily for quantitative culture during therapy and at days 7, 11, and 16 during follow-up.

At day 16, tissue cages were removed, under strictly aseptic conditions, from animals anesthetized with fentanyl-droperidol. After semiquantitative culture on Mueller-Hinton agar [16], tissue cages were incubated in trypticase soy broth for $48 \mathrm{~h}$. Any positive culture identified as $S$. epidermidis was defined as a treatment failure if the isolated strain had the same antimicrobial susceptibility pattern as the inoculated strain. The antibiogram included 29 antimicrobial agents. Each drug regimen was tested with 12 tissue cages, except teicoplanin $(n=22)$ and low-dose rifampin $(n=24)$. Drug combinations were considered synergistic if the outcome differed significantly $(P<.05)$ from monotherapy.

Analysis of tissue-cage fluid. Physicochemical parameters in the infected tissue cages were evaluated by determining $\mathrm{pH}, \mathrm{Po}_{2}$, and $\mathrm{PCO}_{2}$. Heparin-rinsed 1-ml syringes with 21 -gauge hypodermic needles (Monovette; Sarstedt Rommelsdorf, FRG) were used for sampling. Samples were drawn $24 \mathrm{~h}$ after infection with $S$. epidermidis B3972, and were immediately processed in a blood gas analyzer (ABL 300 acid-base-laborat ory; Radiometer Kopenhagen, Copenhagen). In one-third of the samples, hemoglobin concentration exceeded $1.5 \mathrm{~g} / \mathrm{l}$. These fluids were not analyzed because of the buffer capacity of hemoglobin. Blood contamination occasionally resulted from puncture of small vessels during aspiration.

Pharmacokinetics. Pharmacokinetic studies were performed in sterile and infected tissue cages (day 4 of infection with $S$. epidermidis B3972). Every drug was injected ip, except netilmicin, which was given im. Peak levels in serum and in tissue-cage fluid were determined 1 and 3-5 $\mathrm{h}$ after the drug application, respectively. Trough levels in cage fluid were measured at $12 \pm 0.5 \mathrm{~h}$. All antibiotic levels were measured by agar diffusion bioassays [17]. Bacillus subtilis (0453-360, Difco, Detroit) was used as the test strain for ciprofloxacin, vancomycin, teicoplanin, and netilmicin; Micrococcus luteus (ATCC 9341) was used for daptomycin. The dose-response curves were linear in the required range. Antibiotics for the standards were diluted with pooled guinea pig serum (50\%). In a large plate $(30 \times 30 \mathrm{~cm})$, reference standard was placed in three wells and each sample in two wells. Standard and samples were randomly located in different areas of the plate. Results were calculated by microcomputer-assisted exponential regression analysis (HewlettPackard HP41V).

MIC/MBC determinations. MICs were determined by the broth dilution method supplemented with appropriate divalent cations [8]. The inoculum was adjusted from an overnight culture to a concentration of $5 \times 10^{5} \mathrm{cfu} / \mathrm{ml}$. MBCs were performed according to the Manual of Clinical Microbiology [9]. The antibiotic concentration, which reduced the initial inoculum $>99.9 \%$, was read as MBC. MBCs were also determined with bacteria in the stationary phase of growth. For this purpose, we modified the standard method by replacing Mueller-Hinton broth by $0.25 \%$ glucose-supplemented phosphatebuffered saline (PBS), pH 7.4. Under these conditions, bacterial counts remained in the same range $\leqslant 36 \mathrm{~h}$. For daptomycin, glucosesupplemented $(0.25 \%) \mathrm{NaCl} 0.9 \%$, adjusted for $\mathrm{pH} 7.4$ with natriumbicarbonate, was used to provide an ionized $\mathrm{Ca}^{++}$level of $\geqslant 50$ $\mathrm{mg} / \mathrm{l}$. Ionized $\mathrm{Ca}^{++}$levels were determined for any solution used for daptomycin (Nova 2, ionized calcium analyzer; Novabiochemicals, Newton, MA). This concentration of ionized $\mathrm{Ca}^{++}$enables daptomycin's antimicrobial activity in vitro [18]. Experiments were performed in triplicate.

Time-kill curves. Time-kill curves of bacteria in the logarithmic phase of growth were performed in $\mathrm{Ca}^{++}$-supplemented MuellerHinton broth [9]. For kill curves of bacteria in the stationary phase of growth, broth was replaced by glucose-supplemented PBS, pH 7.4. For daptomycin, we used $\mathrm{NaCl}(0.9 \%)$ adjusted with bicarbonate to a $\mathrm{pH} 7.4$ with the above mentioned supplements. Drug concentrations that correspond to standard MBCs were used to kill curves [9]. Samples for plating were diluted 10-fold to minimize antibiotic carryover. The number of cfu was determined at $2,4,6,8,12$, and $24 \mathrm{~h}$, respectively, by plating appropriate dilutions of the culture on Mueller-Hinton agar. The test was processed in a room at a constant $35^{\circ} \mathrm{C}$ to avoid unstable temperatures during handling.

Killing of adherent bacteria. To investigate the antimicrobial activity against adherent bacteria, we developed a novel test procedure. Glass slides $(35 \times 75 \mathrm{~mm})$ were washed in alcohol/ acetone and placed vertically in racks that were transferred in gas-sterilized polyacetal dishes $(100 \times 80 \times 90 \mathrm{~mm})$ (Semadeni AG, Ostermundigen, Switzerland). S. epidermidis B3972 was suspended from a fresh overnight culture in $250 \mathrm{ml}$ of sterile $0.25 \%$ glucose-supplemented PBS ( $\mathrm{pH} \mathrm{7.4)} \mathrm{at} \mathrm{a} \mathrm{final} \mathrm{concentration} \mathrm{of} 8 \times 10^{3} \mathrm{cfu} / \mathrm{ml}$ and then placed in the dishes.

The inoculum was confirmed by plating $0.1 \mathrm{ml}$ directly from each dish onto agar. Four slides, placed in the rack, were incubated in each dish for $24 \mathrm{~h}$ with agitation $(90 \mathrm{rpm})$ at $35^{\circ} \mathrm{C}$. Continuous agitation prevented clusters of adherent bacteria. After this attachment period, bacterial suspension was discarded, and all slides were washed three times in a $0.9 \%$ solution of sterile saline. Both sides of two slides served as controls (adherent inoculum) and were slightly pressed with a forceps on Mueller-Hinton agar petri dishes. Care was taken to keep slides in contact with the agar and to avoid air bubbles. We assumed that any adherent microorganism gave a copy of itself on the agar. The other two slides were transferred with the rack in $\mathrm{Ca}^{++}(50 \mathrm{mg} / 1)$-supplemented trypticase soy broth (TSB) containing antibiotics. This rack was agitated $(90 \mathrm{rpm})$ for another $24 \mathrm{~h}$ at $35^{\circ} \mathrm{C}$ at drug concentrations corresponding to twofold MBCs determined in the logarithmic phase of growth. Again, samples were washed before being pressed on Mueller-Hinton agar. Colonies of controls and samples were counted and expressed as colony-forming units per slide. Experiments were excluded from analysis if adher- 
Table 1. Pharmacokinetic studies of antibiotic levels and MIC of Staphylococcus epidermidis B3972.

\begin{tabular}{|c|c|c|c|c|c|c|c|}
\hline \multirow[b]{2}{*}{ Antibiotic } & \multirow{2}{*}{$\begin{array}{c}\text { Dose } \\
(\mathrm{mg} / \mathrm{kg})^{*}\end{array}$} & \multicolumn{2}{|c|}{ Peak level in serum $(\mu \mathrm{g} / \mathrm{ml})$} & \multicolumn{2}{|c|}{ Level in cage fluids $\ddagger(\mu \mathrm{g} / \mathrm{ml})$} & \multirow{2}{*}{$\begin{array}{c}\text { MIC } \\
(\mu \mathrm{g} / \mathrm{ml})\end{array}$} & \multirow{2}{*}{$\begin{array}{l}\text { Ratio of trough } \\
\text { level to MIC }\end{array}$} \\
\hline & & Guinea pig & Human $\dagger$ & Peak & Trough & & \\
\hline Vancomycin & 15 & 22 & 25 & $8.6(13.9)$ & $2.8 \quad(2.71)$ & 1.0 & $2.8 \quad(2.7)$ \\
\hline Daptomycin & 5 & 15 & 15 & $6.3(10.14)$ & $3.8 \quad(4.15)$ & 1.0 & $3.8 \quad(4.2)$ \\
\hline Teicoplanin & 6.6 & 15 & 20 & $9.6(14.1)$ & $7.7(3.7)$ & 2.0 & $3.9 \quad(1.9)$ \\
\hline Netilmicin & 20 & 67 & 30 & $36 \quad(7.01)$ & $7.3 \quad(0.97)$ & 2.0 & $3.7(0.5)$ \\
\hline Ciprofloxacin & 10 & 3.1 & 2 & $0.95(0.34)$ & $0.11(0.13)$ & 0.06 & $1.8 \quad(2.2)$ \\
\hline Rifampin & 7.5 & 0.49 & 12 & $0.35(0.8)$ & $0.11(0.40)$ & 0.031 & $3.5(13.9)$ \\
\hline Rifampin & 25 & 14.5 & 12 & $8.3 \quad(6.32)$ & $1.88(0.63)$ & 0.031 & $62 \quad(20.3)$ \\
\hline
\end{tabular}

NOTE. MIC = minimum inhibitory concentration.

* Drugs were administered twice daily. Netilmicin was administered intramuscularly; all others were administered intraperitoneally.

$\dagger$ Average of serum peak levels in humans provided by respective manufacturers

$\$$ Ratios in parentheses calculated with the results of infected tissue-cage fluid.

ent bacteria of the controls were $<10^{2}$ or $>10^{3}$ cfu per slide so that each experiment had similar adherent inocula. The percentage kill rate was calculated as 100 - [(cfu per slide on drug-incubated slides)/(cfu per slide on control slides)] $\times 100$.

Statistics. Fisher's exact test was performed for animal studies. Variance component analysis was done for adherence studies using a statistical software (SAS Institute, Cary, NC).

\section{Results}

Pharmacokinetics. Table 1 compares the pharmacokinetic studies in guinea pigs with the MIC of the corresponding drug. For each antibiotic a dosage was chosen that resulted in peak serum levels near those suggested by the drug's manufacturer. With these regimens, peak levels in sterile cage fluids exceeded MBCs for every experimental drug. Trough levels in sterile fluids were below the MBC, but still above MICs for vancomycin, ciprofloxacin, and netilmicin (tables 1 and 2). The ratio of the trough level in sterile cage fluid to MIC was similar for all drugs (1.8-3.9) except rifampin (table 1). The trough level in sterile tissue-cage fluid of the regular rifampin regimen $(25 \mathrm{mg} / \mathrm{kg})$ exceeded the MIC 62 times. Thus, we also tested rifampin at a lower dose $(7.5 \mathrm{mg} / \mathrm{kg})$, providing a trough level:MIC ratio in the same range as the other drugs. Antibiotic levels in infected tissue-cage fluids (table 1, values in parentheses) were in the same range as in sterile fluids, except for netilmicin. As could be expected, these levels were lower in infected than in sterile tissue-cage fluid [19].

Tissue-cage infection. Infection of all cages was initiated by an initial inoculum of $\sim 10^{4}$ cfu of $S$. epidermidis B3972 or $S$. epidermidis ATCC 35983. In control animals, bacterial counts in aspiration fluid fluctuated from $10^{3}$ to $10^{5} \mathrm{cfu} / \mathrm{ml}$, regardless of the initial inoculum.

Treatment results are summarized in figure 1. No spontaneous healing of implant infections occurred in 60 untreated cages, not even after a prolonged (3-month) observation ( $n=$ 4). The infection remained localized around the tissue cages. Infected tissue cages were expelled after $\sim 3$ months. Spontaneous contamination of the cage fluid was observed during the experiment in $5 \%-10 \%$, mostly due to gram-ncgative rods. The emergence of resistance was not observed with any antibiotic regimen.

Teicoplanin and ciprofloxacin, respectively, were the least efficient drugs; rifampin had the highest efficacy $(P<.001)$. Ciprofloxacin did not reduce bacterial counts during treatment (data not shown). The addition of netilmicin to daptomycin significantly improved the cure rate $(P<.01)$. Synergy could not be demonstrated when netilmicin was combined with vancomycin. Rifampin was the only drug that sterilized any implant infection, mostly within $48 \mathrm{~h}$ after the start of treatment. With low-dose therapy $(7.5 \mathrm{mg} / \mathrm{kg})$, bacterial counts fell below the limit of detection, but in $25 \%$ relapse with the same rifampin-sensitive strain occurred. This recurrence could be avoided by adding ciprofloxacin to low-dose rifampin. This combination failed to cure any implant ( 0 of 12) infected by the rifampin-resistant $S$. epidermidis B3972 variant. In all experiments shown in figure 1 , treatment was started $24 \mathrm{~h}$ after inoculation. For rifampin, the most efficient drug, this interval was prolonged to 1 week ( 3 and 7 days). Rifampin ( $25 \mathrm{mg}$ / $\mathrm{kg}$ ) sterilized all 12 implant infections, even when started 7 days after bacterial inoculation.

To check the importance of slime production on antibiotic efficacy, we performed two more series of experiments with S. epidermidis ATCC 35983, known to be a moderate to strong

Table 2. Minimum bactericidal concentration (MBC) of Staphylococcus epidermidis B3972.

\begin{tabular}{|c|c|c|c|}
\hline \multirow[b]{2}{*}{ Antibiotic } & \multicolumn{2}{|c|}{$\begin{array}{l}\text { Phases of bacterial } \\
\text { growth }(\mu \mathrm{g} / \mathrm{ml})\end{array}$} & \multirow{2}{*}{$\begin{array}{c}\text { Fold } \\
\text { increase }\end{array}$} \\
\hline & Logarithmic & Stationary & \\
\hline Vancomycin & 4 & 50 & 12.5 \\
\hline Daptomycin & 2 & 12.5 & 6 \\
\hline Teicoplanin & 4 & 12.5 & 3 \\
\hline Ciprofloxacin & 0.5 & 100 & 200 \\
\hline Rifampin & 0.06 & 0.15 & 2.5 \\
\hline Netilmicin & 8 & 400 & 50 \\
\hline
\end{tabular}


Figure 1. Cure rate of tissue-cage infections with Staphylococcus epidermidis B3972. Guinea pigs with tissue-cage implants were treated with antibiotics as indicated on the $y$ axis. Numbers of infections: controls, 60; antibiotics, 12 each, except teicoplanin, 22, and rifampin $(7.5 \mathrm{mg} / \mathrm{kg}), 24$. Rifampin at 25 $\mathrm{mg} / \mathrm{kg}$ was significantly more efficient than at $7.5 \mathrm{mg} / \mathrm{kg}(P<.01$, Fisher's exact test).

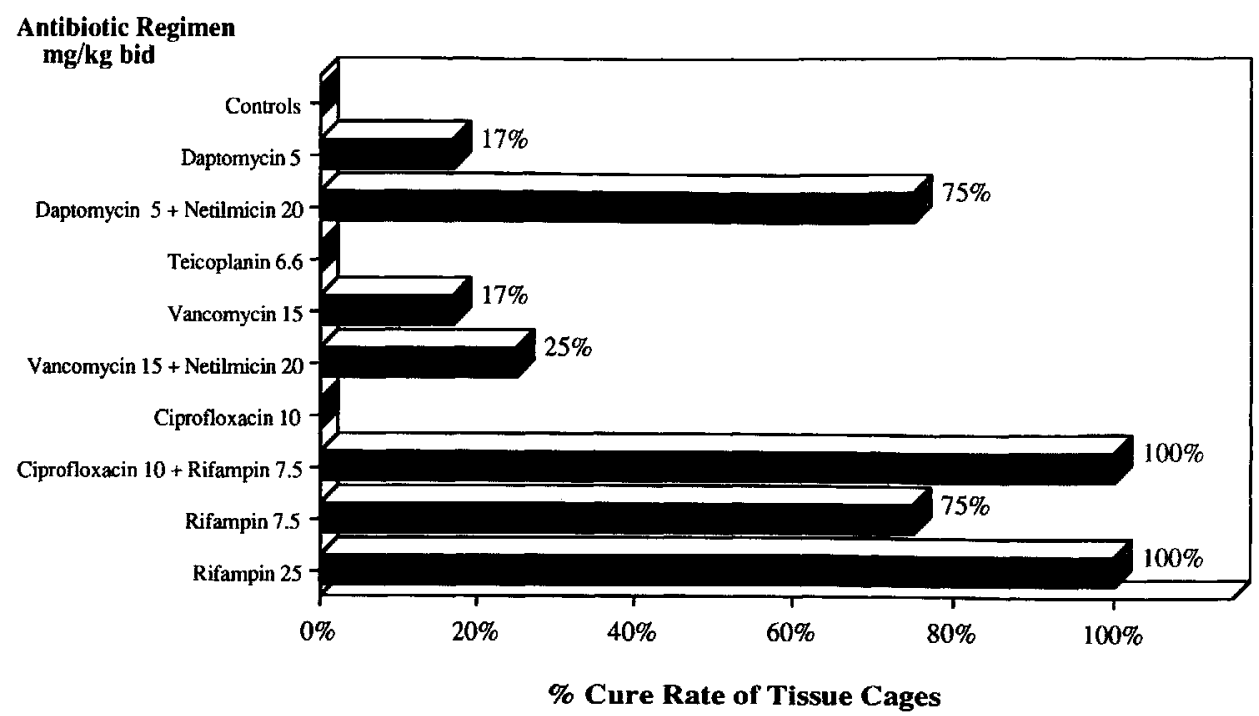

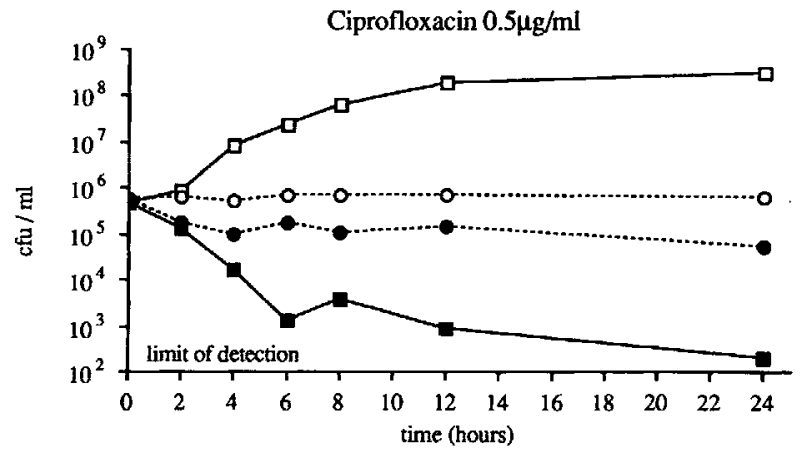
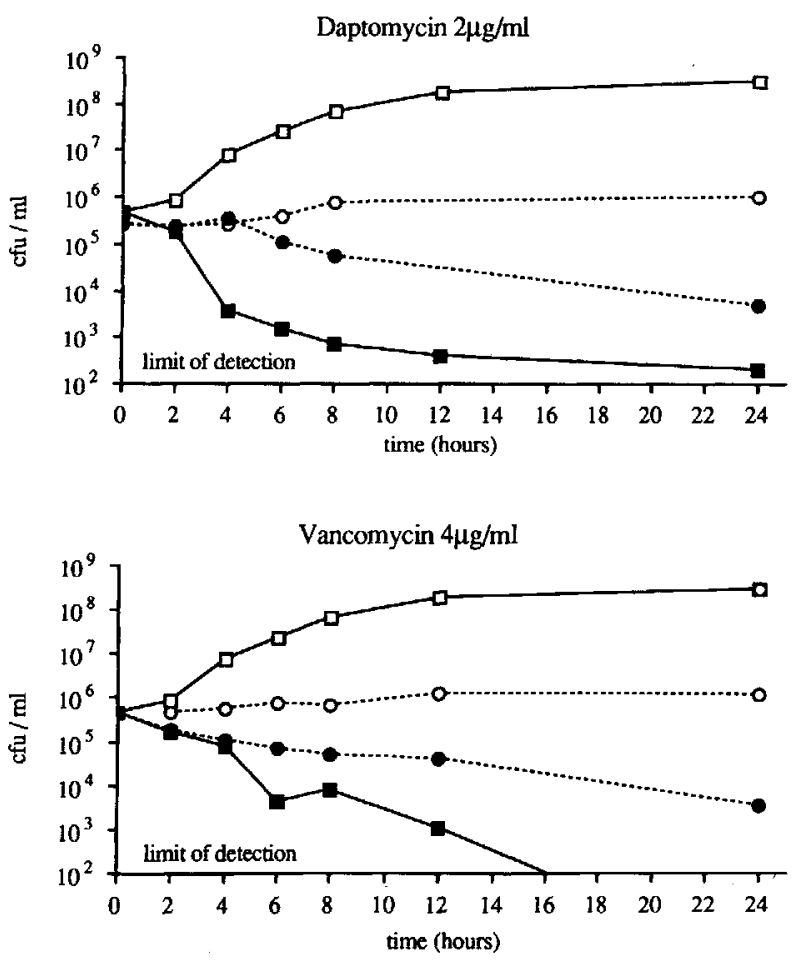

slime producer [14]. With this strain also, any tissue cage ( $n=$ 8 ) in control animals remained infected during the experiment. Rifampin (25 mg/kg) still sterilized all 12 tissue cages, whereas ciprofloxacin did not cure any infection ( 0 of 12 ).

Characteristics of tissue-cage fluid. In view of the different cure rates by antibiotics that reached local levels exceeding MICs at any time, we analyzed some characteristics of the infected tissue-cage fluids that might influence the in vivo efficacy of antibiotics. A slight acidosis ( $\mathrm{pH} 7.18 \pm 0.04, n=$ 12) and a moderately decreased $\mathrm{Po}_{2}(7.67 \pm 0.7 \mathrm{kPa})$ were measured.

$M B C s$ and time-kill curves in stationary and logarithmic phases of bacterial growth. Microorganisms involved in implant-associated infections may be in stationary growth phases. We thus sought in vitro tests with a better predictive value than the standard MIC and MBC, which are determined in the logarithmic phase of growth [9]. Table 2 shows that MBCs of S. epidermidis B3972 determined with bacteria in the stationary growth phase were up to 200 times higher (ciprofloxacin) than obtained with bacteria in the logarithmic phase of growth. Rifampin, teicoplanin, and daptomycin all had almost the same efficacy on nongrowing as on growing staphylococci. To further characterize these observations, we performed kill curves in stationary and logarithmic growth phases. The results of representative experiments are summarized in figures 2 and 3 . Figure 2 shows drugs with diminished activity on nongrowing bacteria. In contrast, rifampin and teicoplanin (figure 3 ) had a nearly identical killing rate in both systems. However, rifampin acted much faster than

Figure 2. Time-kill studies of Staphylococcus epidermidis B3972. Concentration of antibiotic corresponds to minimum bactericidal concentration in logarithmic phase of growth. Controls and antibiotics in logarithmic growth phases, respectively $(\square, \mathbf{\square}$,$) ; controls$ and antibiotics in stationary growth phases, respectively $(0, \bullet)$. 

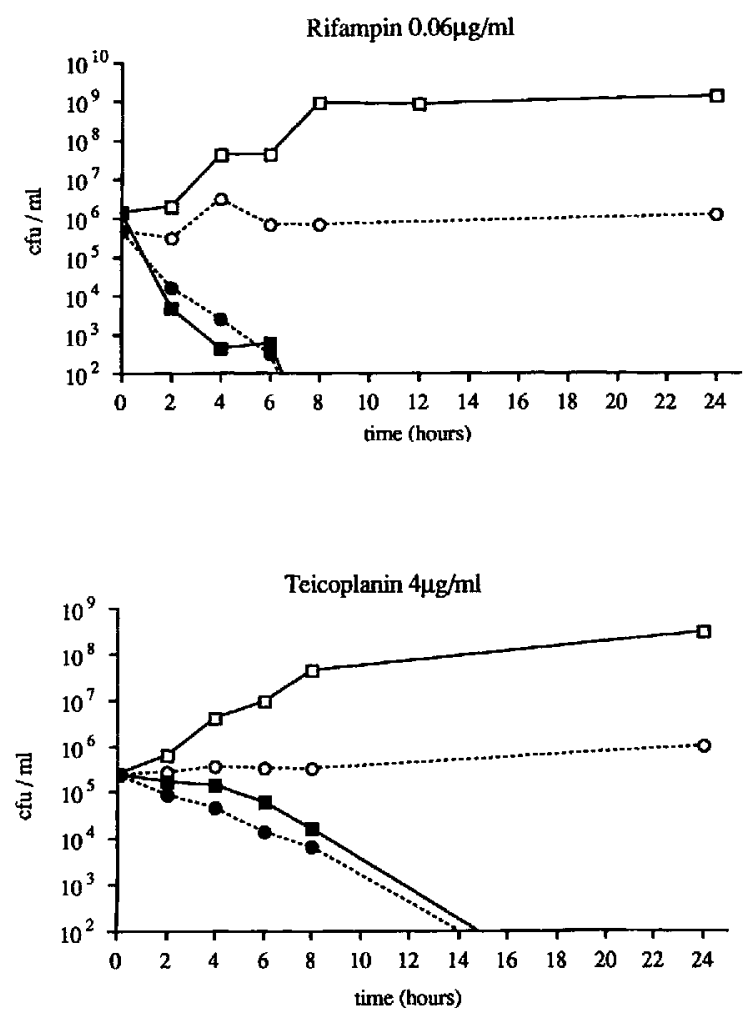

Figure 3. Time kill studies of Staphylococcal epidermidis B3972. Concentration of antibiotic corresponds to minimum bacterical concentration in logarithmic growth phase. Controls and antibiotics in logarithmic growth phase $(\square, \square)$; controls and antibiotics in stationary growth phases $(O,-)$.

teicoplanin. In the time-kill curve, teicoplanin $(4 \mu \mathrm{g} / \mathrm{ml})$ showed a killing rate of $>99.9 \%$, which contrasted with the stationary MBC of $12.5 \mu \mathrm{g} / \mathrm{ml}$; however, this may be due to the different techniques used. The antibiotic combinations used in the animal model did not improve the killing by the single agent (data not shown).

Drug efficacy on adherent S. epidermidis B3972. Since in device-related infections bacterial adhesion is crucial, we tested an additional parameter, drug efficacy on adherent bacteria. With an initial inoculum of $8 \times 10^{3} \mathrm{cfu} / \mathrm{ml}, 330 \pm 13$ cfu per slide (mean $\pm \mathrm{SE}, n=92$ ) adhered to the glass slides. More than $10^{3} \mathrm{cfu}$ per slide adhered with inocula exceeding $8 \times 10^{4} \mathrm{cfu} / \mathrm{ml}$. The variability among different assays with the same drug was always lower than among different drugs ( $F=11.86, P<.01)$, confirming the reproducibility of the assay. Figure 4 summarizes the results of four or more experiments. Rifampin was the most efficient drug with a mean killing rate of $99.7 \%$ by incubation of adherent bacteria at the doubled MBC.

\section{Discussion}

We previously analyzed host defense mechanisms in the animal model used in this study $[2,3,12]$. Similar to humans, guinea pigs are highly susceptible to foreign-body infections [3]. Thus this model was used to test antibiotics for their ability to sterilize device-related infections. Clinical data concerning the antibiotic treatment of such infections are scarce and difficult to interpret. Therefore, criteria for surgical versus antibiotic treatment of the different implant infections are not well established [1]. This reflects the difficulty in performing clinical studies under controlled conditions with unambiguous criteria to determine efficacy after prolonged follow-up periods.

To enable attachment and adherence of bacteria to the implant [5], we started the antimicrobial treatment not earlier than $24 \mathrm{~h}$ after inoculation. Short-term therapy was chosen for detecting antimicrobial agents with excellent efficacy. Rifampin was the most efficient drug; however, the extremely low MIC compared to the tissue-cage trough level could be a trivial explanation for its high efficacy. To correct for this, we used a low-dose regimen of rifampin that resulted in a ratio of trough level in tissue-cage fluid to MIC similar to that of the other drugs. At this low dose, rifampin was still the most efficient drug.

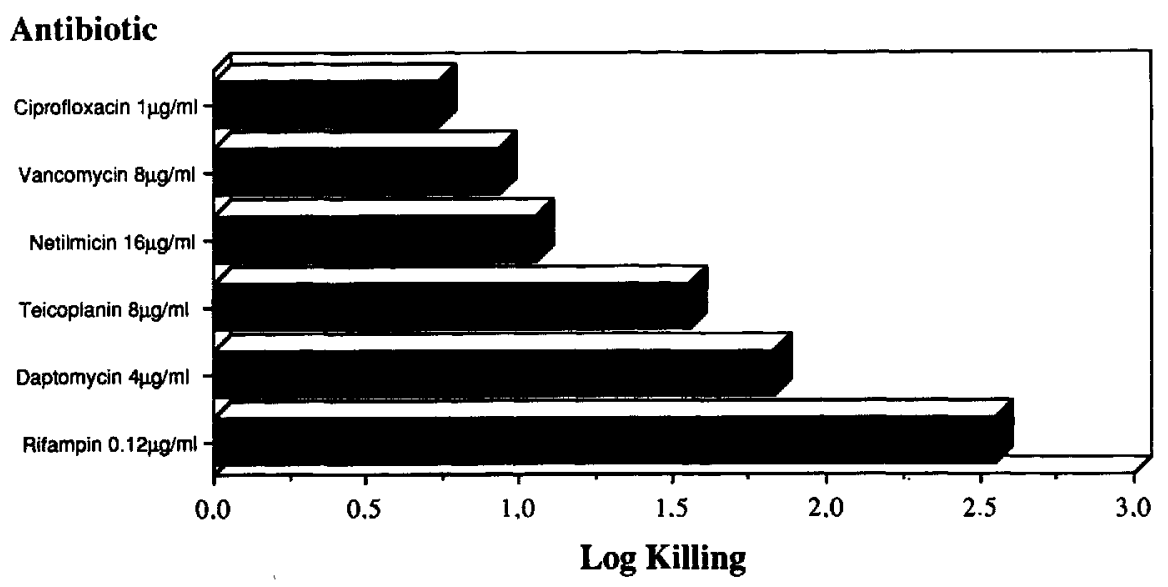

Figure 4. Log killing of adherent Staphylococcus epidermidis B3972. Assay was performed at drug concentrations twice the minimum bactericidal concentrations. Concentrations are shown on $y$ axis. Killing rate was determined as follows: $100-$ I (cfu per slide on drug incubated slides)/(cfu per slide on control slides)] $\times 100$, expressed as $\log _{10}$ killing. 
Ciprofloxacin had no detectable efficacy in the animal model. This failure could not be predicted by the standard MIC, which exceeded sterile and infected tissue-cage fluid trough levels twofold. The slightly decreased $\mathrm{pH}$ of the infected tissue-cage fluid could not explain the lack of antimicrobial activity.

In contrast to regular MICs and MBCs, bacterial MBCs under stationary growth phase were predictive for the outcome of tissue-cage infections. The low performance of ciprofloxacin on nongrowing bacteria was surprising since Zeiler and Grohe [20] showed a high efficacy of this antibiotic on Escherichia coli in the stationary phase. However, this quality of ciprofloxacin was later shown to be specific for some gram-negative rods $[21,22]$. The low antistaphylococcal activity of cyprofloxacin has also been confirmed by clinical data. Greenberg et al. [23] reported that none of six patients with osteomyelitis caused by Staphylococcus aureus (monoculture) was cured with ciprofloxacin therapy.

In our experiments the stationary-phase $\mathrm{MBC}$ was surpassed only by the tissue-cage peak and trough levels in animals receiving rifampin. This was the sole single-drug regimen with a high success rate. Several authors have reported the rapid emergence of rifampin-resistant staphylococci during exposure to this drug [24, 25]. Unlike Archer et al. [25], we did not detect the emergence of rifampin-resistant $S$. epidermidis during treatment with rifampin, probably because the bacterial counts in tissue-cage fluid remained at a low level. Nevertheless, in treatment of human infections, rifampin should always be used in combination with other drugs. Vancomycin, which has a much lower volume of distribution than rifampin, is probably not the ideal drug to combine with rifampin $[26,27]$. Thus, we tested the effect of ciprofloxacin in combination with low-dose rifampin. The improved cure rate indicates in vivo synergism of this combination. We also sought a possible nonantimicrobial effect of rifampin (e.g., antiadhesive potency) and repeated this experiment with the rifampin-resistant variant. This combination did not cure any tissue-cage infection, thus precluding a nonspecific effect of rifampin.

As a further diagnostic parameter for the antimicrobial activity in foreign-body infections, we measurcd the killing of in vitro adherent bacteria by antibiotics. Our assay proved simple and reproducible because the variability among different assays with the same drug was always lower than between different drugs.

Although the assay is fastidious, there are several possible pitfalls. The number of adherent bacteria is crucial. Also, polyacetal dishes give better reproducible results than glass dishes (data not shown), and the adherent bacteria on each slide reproduce better if the dishes are gently agitated during the whole procedure. With this assay, rifampin again had excellent efficacy. The drug was the only one that eliminated $>2.5$ logs of the adherent bacteria after incubation for $24 \mathrm{~h}$ in a drug concentration corresponding to twofold MBC. The excellent efficacy of rifampin in our in vitro assay and in the animal model concurs with that found in arterial graft infections in dogs [7].

Daptomycin and teicoplanin were the second best antibiotics, with a 1.7-log killing of adherent $S$. epidermidis. This contrasted with the poor in vivo results of teicoplanin. However, the drug concentration in tissue-cage fluid at trough levels did not exceed the stationary-phase MBC. Possibly the failure of teicoplanin was due to insufficient drug levels such as reported in clinical studies [28]. Daptomycin may also have been used at inadequate levels. All other antibiotics tested killed $<1 \log$ of adherent microorganisms. Ciprofloxacin again had the lowest activity. Gristina et al. [29] had similar findings with another method. They recently showed that adherent coagulase-negative staphylococci have generally higher MBCs than do planktonic bacteria.

In conclusion, drug efficacy in the treatment of devicerelated experimental $S$. epidermidis infections may be predicted by the described in vitro assays. In view of our experimental data, we treated some staphylococcal infections associated with orthopedic implants with an antibiotic combination containing rifampin. With follow-up observations of $>1$ year, disappearance of signs of inflammation could be observed (unpublished data). These preliminary data should be confirmed in a controlled clinical trial with the described assays as a guide for the choice of antibiotics.

\section{Acknowledgment}

We thank Peter Schumacher, Biocenter Basel, Switzerland, for assistance in statistical analyses.

\section{References}

1. Dougherty SH, Simmons RL. Infections in bionic man: the pathobiology of infections in prosthetic devices (parts I and II). Curr Probl Surg 1982;19:219-264, 268-319

2. Zimmerli W, Lew PD, Waldvogel FA. Pathogenesis of foreign body infection. Evidence for a local granulocyte defect. J Clin Invest 1984; 73:1191-1200

3. Zimmerli W, Waldvogel FA, Vaudaux $P$, Nydegger UE. Pathogenesis of foreign body infection: description and characteristics of an animal model. J Infect Dis 1982;146:487-497

4. Vaudaux PE, Zulian G, Huggler E, Waldvogel FA. Attachment of Staphylococcus aureus to polymethylmethacrylate increases its resistance to phagocytosis in foreign body infection. Infect Immun 1985;50: $472-477$

5. Gristina AG. Biomaterial-centered infection: microbial adhesion versus tissue infiltration. Science 1987;237:1588-1595

6. Gristina AG, Costerton JW. Bacterial adherence to biomaterials and tissue. J Bone Joint Surg [Am] 1985;67A:264-273

7. Bergamini TM, Bandyk DF, Govostis DF, Kaebnick HW, Towne JB. Infection of vascular prostheses caused by bacterial biofilms. J Vasc Surg 1988;7:21-30

8. National Committee for Clinical Laboratory Standards. Methods for dilution antimicrobial susceptibility tests for bacteria that grow aerobically. 2nd ed. Tentative standard. NCCLS document M7-T2, Villanova, PA: NCCLS, 1988

9. Schoenknecht FD, Sabath LD, Thornsberry C. Susceptibility tests: spe- 
cial tests. In: Lennette EH, Balows A, Hausler WJ Jr, Shadomy HJ, eds. Manual of clinical microbiology. 4th ed. Washington, DC: American Society for Microbiology, 1985;1000-1008

10. Tuomanen E, Cozens R, Tosch W, Zak O, Tomasz A. The rate of killing of Escherichia coli by $\beta$-lactam antibiotics is strictly proportional to the rate of bacterial growth. J Gen Microbiol 1986;132:1297-1304

11. Blaser $\mathbf{J}$, Weinmann $O$, Luethy $R$. Poor antibiotic activity against adherent bacteria [abstract 782]. In: Program and abstracts of the 28th Interscience Conference on Antimicrobial Agents and Chemotherapy (Los Angeles). Washington, DC: American Society for Microbiology, 1988

12. Zimmerli W, Waldvogel FA. Models of foreign-body infections. In: Zak O, Sande MA. Experimental models in antimicrobial chemotherapy. Vol I. London: Academic Press, 1986:295-317

13. Hartstein AI, Valvano MA, Morthland VH, Fuchs PC, Potter SA, Crosa JH. Antimicrobic susceptibility and plasmid profile analysis as identity tests for multiple blood isolates of coagulase-negative staphylococci. J Clin Microbiol 1987;25:589-593

14. Christensen GD, Simpson WA, Bisno AL, Beachey EH. Adherence of slime-producing strains of Staphylococcus epidermidis to smooth surfaces. Infect Immun 1982;37:318-326

15. Christensen GD, Simpson WA, Younger JJ, Baddour LM, Barrett FF, Melton DM, Beachey EH. Adherence of coagulase-negative staphylococci to plastic tissue culture plates: a quantitative model for the adherence of staphylococci to medical devices. J Clin Microbiol 1985;22:996-1006

16. Maki DG, Weise CE, Sarafin HW. A semiquantitative culture method for identifying intravenous-catheter-related infection. N Engl J Med 1977;296:1305-1309

17. Edberg SC, Barry AL, Young LS. Therapeutic drug monitoring: antimicrobial agents. In: Morello JA, ed. Cumulative techniques and procedures in clinical microbiology, Cumitech 20. Washington, DC: American Society for Microbiology, 1984:1-8

18. Andrew JH, Wale MCJ, Wale LJ, Greenwood D. The effect of cultural conditions on the activity of LY146032 against staphylococci and streptococci. J Antimicrob Chemother 1987;20:213-221
19. Vaudaux P. Peripheral inactivation of gentamicin. J Antimicrob Chemother 1981;8(suppl A):17-25

20. Zeiler $\mathbf{H J}$, Grohe $\mathbf{K}$. The in vitro and in vivo activity of ciprofloxacin. Eur J Clin Microbiol Infect Dis 1984;3:339-343

21. Zeiler HJ. Evaluation of the in vitro bactericidal action of ciprofloxacin on cells of Escherichia coli in the logarithmic and stationary phases of growth. Antimicrob Agents Chemother 1985;28:524-527

22. Chalkley LJ, Koornhof HJ. Antimicrobjal activity of ciprofloxacin against Pseudomonas aeruginosa, Escherichia coli, and Staphylococcus aureus determined by the killing curve method: antibiotic comparisons and synergistic interactions. Antimicrob Agents Chemother 1985; 28:331-342

23. Greenberg RN, Kennedy DJ, Reilly PM, Luppen KL, Weinandt WJ, Bollinger MR, Aguirre F, Kodesch F, Saeed AMK. Treatment of bone, joint, and soft-tissue infections with oral ciprofloxacin. Antimicrob Agents Chemother 1987;31:151-155

24. Tshefu K, Zimmerli W, Waldvogel FA. Short-term administration of rifampin in the prevention or eradication of infection due to foreign bodies. Rev Infect Dis 1983;5(suppl 3):S474-\$480

25. Archer GL, Johnston JL, Vazquez GJ, Haywood HB III. Efficacy of antibiotic combinations including rifampin against methicillin-resistant Staphylococcus epidermidis: in vitro and in vivo studies. Rev Infect Dis 1983;5(suppl 3):S538-S542

26. Brumfitt W, Hamilton-Miller J. Methicillin-resistant Staphylococcus aureus. N Engl J Med 1989;320:1188-1196

27. Eng RHK, Smith SM, Tillem M, Cherubin C. Rifampin resistance. Development during the therapy of methicillin-resistant Staphylococcus aureus infection. Arch Intern Med 1985;145:146-148

28. Calain P, Krause KH, Vaudaux P, Auckenthaler R, Lew D, Waldvogel F, Hirschel B. Early termination of a prospective, randomized trial comparing teicoplanin and flucloxacillin for treating severe staphylococcal infections. J Infect Dis 1987;155:187-191

29. Gristina AG, Jennings RA, Naylor PT, Myrvik QN, Webb LX. Comparative in vitro antibiotic resistance of surface-colonizing coagulasenegative staphylococci. Antimicrob Agents Chemother 1989;33: 813-816 